\title{
Insight into the activation mechanism of Escherichia coli octaprenyl pyrophosphate synthase derived from pre-steady-state kinetic analysis
}

\author{
Jian-Jung Pan ${ }^{a}$, Tun-Hsun Kuo ${ }^{b}$, Yi-Kai Chen ${ }^{a}$, Lee-Wei Yang ${ }^{\text {a }}$, \\ Po-Huang Liang a,b,* \\ a Institute of Biological Chemistry, Academia Sinica, Taipei 11529, Taiwan \\ b Institute of Biochemical Sciences, National Taiwan University, Taipei 10098, Taiwan
}

Received 26 July 2001; received in revised form 11 September 2001; accepted 13 September 2001

\begin{abstract}
Octaprenyl pyrophosphate synthase (OPPs) catalyzes the sequential condensation of five molecules of isopentenyl pyrophosphate with farnesyl pyrophosphate to generate all-trans $\mathrm{C}_{40}$-octaprenyl pyrophosphate, which constitutes the side chain of ubiquinone. Due to the slow product release, a long-chain polyprenyl pyrophosphate synthase often requires detergent or another factor for optimal activity. Our previous studies in examining the activity enhancement of Escherichia coli undecaprenyl pyrophosphate synthase have demonstrated a switch of the rate-determining step from product release to isopentenyl pyrophosphate (IPP) condensation reaction in the presence of Triton [12]. In order to understand the mechanism of enzyme activation for $E$. coli OPPs, a single-turnover reaction was performed and the measured IPP condensation rate $\left(2 \mathrm{~s}^{-1}\right)$ was 100 times larger than the steady-state rate $\left(0.02 \mathrm{~s}^{-1}\right)$. The high molecular weight fractions and Triton could accelerate the steady-state rate by 3 -fold $\left(0.06 \mathrm{~s}^{-1}\right)$ but insufficient to cause full activation (100-fold). A burst product formation was observed in enzyme multiple turnovers indicating a slow product release. (C) 2002 Elsevier Science B.V. All rights reserved.
\end{abstract}

Keywords: Pre-steady-state kinetics; Prenyltransferase; Rapid quench; Single turnover

\footnotetext{
Abbreviations: IPP, isopentenyl pyrophosphate; FPP, farnesyl pyrophosphate; UPPs, undecaprenyl pyrophosphate synthase; UPP, undecaprenyl pyrophosphate; OPPs, octaprenyl pyrophosphate synthase; OPP, octaprenyl pyrophosphate; SPPs, solanesyl pyrophosphate synthase; HMF, high molecular weight fraction; BSA, bovine serum albumin; PCR, polymerase chain reaction; NiNTA, nickel nitrilotriacetic acid; Tris, tris(hydroxymethyl)aminomethane; HEPES, 4-(2-hydroxyethyl)-1-piperazineethanesulfonic acid; EDTA, ethylenediaminetetraacetic acid; SDSPAGE, sodium dodecyl sulfate-polyacrylamide gel electrophoresis; TLC, thin layer chromatography

* Corresponding author, at address a.

Fax: +886-2-2788-97-59.

E-mail address: phliang@gate.sinica.edu.tw (Po-Huang Liang).
}

\section{Introduction}

Isoprenoid compounds are widely distributed in nature and serve a variety of important biological functions [1]. Using a five-carbon isopentenyl pyrophosphate (IPP) as the building block, isoprenoids are synthesized by a group of enzymes called prenyltransferases, that catalyze the multiple IPP condensation reactions with allylic pyrophosphate for chain elongation. The prenyltransferase reaction results in a trans or cis double bond during each IPP condensation and the enzymes were thus classified as $Z$ - and $E$-type, respectively. In general, $Z$-type prenyltransferases catalyze the formation of long-chain poly- 
prenyl pyrophosphates while $E$-type enzymes synthesize shorter products [2]. Two types of enzymes share no homology in primary sequence $[3,4]$ and have a completely different fold in the three-dimensional structure [5].

Because of the slow product release, some polyprenyl pyrophosphate synthases, especially those that synthesize long-chain products, require detergent, phospholipid or another factor for efficient enzyme turnover [1]. The $\mathrm{C}_{55}$-undecaprenyl pyrophosphate synthase (UPPs) that catalyzes condensation of eight IPP with farnesyl pyrophosphate (FPP) requires Triton or phospholipid for maximal activity [6-11]. We found its activity was $0.013 \mathrm{~s}^{-1}$ in the absence of Triton and was increased 190-fold to 2.5 $\mathrm{s}^{-1}$ in the presence of $0.1 \%$ Triton [12]. The IPP condensation rate measured under enzyme singleturnover ([UPPs] $>[\mathrm{FPP}]$ ) condition where the product release was not limiting the reaction rate, was 2.5 $\mathrm{s}^{-1}$. Obviously, Triton participates in the acceleration of the product release and switches the rate-limiting step to IPP condensation [12]. However, a high molecular weight fraction (HMF) was identified from the soluble cell extract of Micrococcus luteus, which could enhance activity of the solanesyl pyrophosphate synthase (SPPs). SPPs synthesizes all-trans long-chain $\mathrm{C}_{45}$-solanesyl pyrophosphate [13]. It was reported that HMF increased SPPs activity by up to 3-fold. Bovine serum albumin (BSA) and several detergents were found to be equally effective in stimulating the reaction rate of SPPs. It was proposed that a putative polyprenyl carrier protein (PCP) in the HMF might interact with SPPs enzyme and/or bind a hydrophobic product to facilitate product release from the active site. However, without knowing the details of the kinetic pathway of the enzyme, the mechanism of enzyme activation could not be understood. The question of whether the 3-fold activation represented the complete switch of the rate-limiting step was raised.

Octaprenyl pyrophosphate synthase (OPPs) catalyzes the chain elongation of FPP via sequential condensation reactions with IPP to generate $\mathrm{C}_{40}$-octaprenyl pyrophosphate (OPP) as shown in Scheme 1 $[14,15]$. This enzyme activity is required to make the side chain of ubiquinone and menaquinone $[16,17]$, which is a component of electron transfer system to produce ATP. Dimer formation of the en- zyme is essential for chain length determination of ubiquinone [18]. The Escherichia coli OPPs had been shown to be activated by PCP in a way similar to the SPPs [1]. However, the PCP shows no effect on undecaprenyl pyrophosphate synthase. Therefore, it was concluded that PCP acts specifically on $E$-type prenyltransferase with chain lengths of $\mathrm{C}_{40}, \mathrm{C}_{45}$ and $\mathrm{C}_{50}$ [1]. In the present study, we have investigated the activation of $E$. coli octaprenyl pyrophosphate synthase by different agents. The multiple IPP condensation reactions catalyzed by OPPs were examined using a pre-steady-state kinetic approach to determine the rate constant of each step. The difference between the rates of IPP condensation and product release may allow the prediction of the effect of a possible E. coli cellular factor in stimulating OPPs to be made, as if it could fully change the enzyme rate-limiting step from product release to IPP condensation. Furthermore, the kinetic pathway of the $E$. coli OPPs is compared to that previously determined for UPPs, a Z-type prenyltransferase, to understand the differences in the mechanism of chain elongation and product release catalyzed by the $Z$ and $E$-type enzymes of long-chain polyprenyl pyrophosphate synthesis.
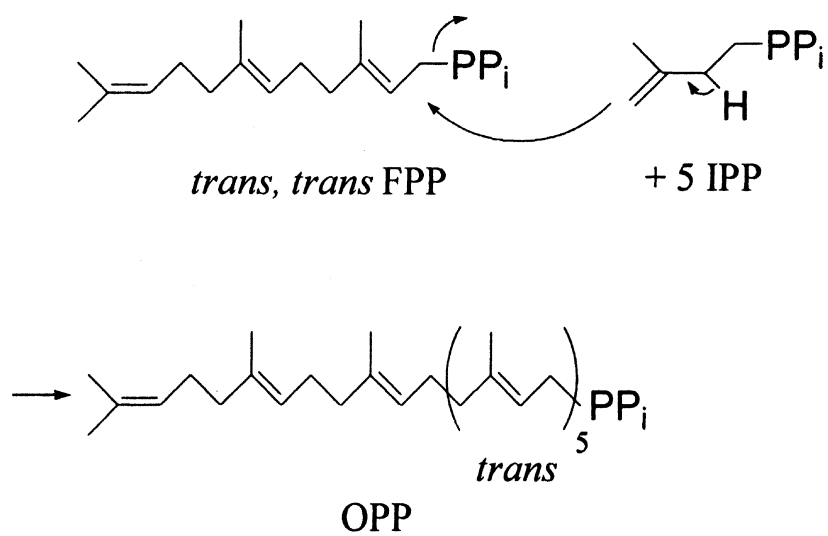

Scheme 1. The octaprenyl pyrophosphate synthase catalyzed chain elongation of $\mathrm{C}_{15}$-farnesyl pyrophosphate to $\mathrm{C}_{40}$-octaprenyl pyrophosphate via sequential condensation reactions of five molecules of $\mathrm{C}_{5}$-isopentenyl pyrophosphate. 


\section{Materials and methods}

\subsection{Reagents}

$\left[{ }^{14} \mathrm{C}\right] \mathrm{IPP}(55 \mathrm{mCi} / \mathrm{mmol})$ radiolabeled substrate was purchased from Amersham Pharmacia Biotech and FPP was a product of Sigma. Reverse phase thin layer chromatography (TLC) for product analysis was obtained from Merck (Darmstadt, Germany). Taq DNA polymerase was purchased from Gibco Life Technologies. The plasmid mini-prep kit, DNA gel extraction kit and nickel nitrilotriacetic acid (NiNTA) were products of Qiagen. Potato acidic phosphatase (2 units $/ \mathrm{mg}$ ) was purchased from Boehringer Mannheim. The pET-32Xa/LIC vector, competent cells E. coli JM109 and BL21 (DE3), T4 DNA polymerase, Factor Xa, and thrombin were obtained from Novagen. All other buffers and reagents were of the highest commercial purity.

\subsection{Overproduction of OPPs from E. coli Bos-12}

The gene encoding OPPs from E. coli Bos-12 was amplified by polymerase chain reaction (PCR) using genomic DNAs as template. The forward primer 5'-TGTTCACAGTAAGGTAATCGG-3' located upstream from the start codon and the reverse primer 5'-ATACTCCTGATGGCCTATTGCT-3' downstream from the stop codon were employed. The amplified OPPs gene purified from $0.8 \%$ agarose gel electrophoresis was used as a template for the second PCR. The PCR reaction was then performed to create a Factor Xa cleavage site and the sequences complementary to the vector $\mathrm{pET} 32 \mathrm{Xa} / \mathrm{LIC}$ for ligation independent cloning. The forward primer was 5'-GGTATTGAGGGTCGCATGAATTTAGAAAAAATC-3' and the reverse primer was 5'-AGAGGAGAGTTAGAGCCAATTAACGATCGCGTT - $3^{\prime}$. The PCR product was purified and treated with $\mathrm{T} 4$ DNA polymerase in the presence of dGTP to create sticky ends for ligation. E. coli JM109 transformed with plasmid was grown overnight at $37^{\circ} \mathrm{C}$ on an agar plate containing ampicillin. A single colony resistant to ampicillin was selected and grown in $5 \mathrm{ml}$ of LB medium containing $100 \mu \mathrm{g} / \mathrm{ml}$ ampicillin overnight. The plasmid was collected from the culture by the plasmid mini-prep kit and its whole OPPs gene was sequenced using the dideoxy chain termination method. The plasmid with the correct gene sequence (the same as the reported OPPs sequence) was then transformed into expression host E. coli strain BL21 (DE-3) for overproduction of recombinant OPPs. A single transformant was grown overnight at $37^{\circ} \mathrm{C}$ in LB containing ampicillin $(100 \mu \mathrm{g} / \mathrm{ml})$. Two liters of fresh LB medium plus $100 \mu \mathrm{g} / \mathrm{ml}$ ampicillin inoculated with $20 \mathrm{ml}$ overnight cultures were grown to $\mathrm{OD}_{600} 0.6$ before induction with $1 \mathrm{mM}$ isopropyl $\beta$ D-thiogalactopyranoside. The cells were induced for $4 \mathrm{~h}$ at $37^{\circ} \mathrm{C}$ before harvest.

\subsection{Purification of recombinant OPPs}

The following enzyme purification was carried out at $4^{\circ} \mathrm{C}$. The $10 \mathrm{~g}$ cell paste yielded from the 21 culture was suspended in $100 \mathrm{ml}$ of lysis buffer containing $25 \mathrm{mM}$ Tris $(\mathrm{pH} 7.5)$, and $150 \mathrm{mM} \mathrm{NaCl}$. The solution was passed to a French press (AIMAMINCO Spectronic Instruments) to disrupt the cells and the lysate was centrifuged to remove debris. The cell free extract was loaded onto a $10 \mathrm{ml}$ NiNTA column previously equilibrated with $50 \mathrm{ml}$ of buffer containing $25 \mathrm{mM}$ Tris ( $\mathrm{pH} 7.5), 150 \mathrm{mM} \mathrm{NaCl}$ and $5 \mathrm{mM}$ imidazole. The column was washed with the same buffer until the $A_{280}$ reached baseline and was further washed with buffer containing $30 \mathrm{mM}$ imidazole. The OPPs with His tag was finally eluted with $25 \mathrm{mM}$ Tris ( $\mathrm{pH} 7.5$ ), $150 \mathrm{mM} \mathrm{NaCl}$ and $300 \mathrm{mM}$ imidazole buffer. The protein solution was dialyzed against $2 \times 2 \mathrm{~L}$ buffer $(25 \mathrm{mM}$ Tris, $\mathrm{pH} 7.5$, and 150 $\mathrm{mM} \mathrm{NaCl}$ ).

The OPPs with His tag was digested using a thrombin cleavage site located in the $\mathrm{N}$-terminus of the recombinant protein for tag removal. This cleavage gave an additional 33 amino acid residues on the OPPs N-terminus, which did not change the enzyme activity. After the treatment of thrombin for tag cleavage the reaction mixture was loaded onto a NiNTA column. The OPPs in flow through (25 $\mathrm{mM}$ Tris, $\mathrm{pH} 7.5,150 \mathrm{mM} \mathrm{NaCl}$ and $5 \mathrm{mM}$ imidazole) was highly pure according to SDS-PAGE. The protein sample was dialyzed with buffer $(25 \mathrm{mM}$ Tris, $\mathrm{pH} 7.5$ and $150 \mathrm{mM} \mathrm{NaCl}$ ) for storage at $-80^{\circ} \mathrm{C}$. 


\subsection{Steady-state $K_{m}$ and $k_{\text {cat }}$ measurements}

The OPPs reaction was initiated by adding 0.05 $\mu \mathrm{M}$ enzyme to a mixture containing various concentrations of FPP $(0.2-10 \mu \mathrm{M})$ and $\left[{ }^{14} \mathrm{C}\right] \mathrm{IPP}(1-50 \mu \mathrm{M})$ in $100 \mathrm{mM}$ HEPES ( $\mathrm{pH} 7.5), 50 \mathrm{mM} \mathrm{KCl}$, and 0.5 $\mathrm{mM} \mathrm{MgCl} 2$ buffer at $25^{\circ} \mathrm{C}$. The enzyme concentration used in all experiments was determined from its absorbance at $280 \mathrm{~nm}\left(\varepsilon_{280 \mathrm{~nm}}=20280 \mathrm{M}^{-1} \mathrm{~cm}^{-1}\right)$. Within $10 \%$ substrate depletion, portions of the reaction mixture were periodically withdrawn and the enzyme reaction was terminated by mixing with 10 mM EDTA (final concentration) and the product was extracted with 1-butanol. The initial rate was calculated by determining the concentration of product formed or IPP consumed at each time point by counting the ${ }^{14} \mathrm{C}$ radioactivity in butanol phase (product) and in aqueous phase (IPP) using a Beckmann LS6500 scintillation counter. The kinetic constants were obtained by fitting the data of the initial rate vs. [substrate] to the Michaelis-Menten equation using KaleidaGraph computer software (Synergy software). The $k_{\text {cat }}$ was calculated from $V_{\max } /[\mathrm{E}]$.

$v_{0}=V_{\max }[\mathrm{S}] /\left(K_{\mathrm{m}}+[\mathrm{S}]\right)$

where $v_{0}$ is the initial velocity, [E] is the enzyme concentration, $[\mathrm{S}]$ is the substrate concentration, $V_{\max }$ is the maximum velocity and $K_{\mathrm{m}}$ is the Michaelis constant.

\subsection{Evaluation of possible OPPs activators and purification of cellular stimulator}

Each of the reagents including the detergents $n$ octyl glucoside, Tween 80, deoxycholic acid, CHAPS and Triton X-100 at $0.1 \%$ final concentration and BSA $(1 \mathrm{mg} / \mathrm{ml})$ was added to an assay solution and the rate of catalysis was measured according to the procedure described above. To obtain HMF from $E$. coli lysate, a similar approach to the one reported previously for the preparation of HMF from $M$. luteus cell extract was used [13]. The cell free extract of E. coli was loaded onto a DEAE-Sepharose column $(2.6 \mathrm{~cm} \times 15 \mathrm{~cm})$ equilibrated with $25 \mathrm{mM}$ Tris $(\mathrm{pH}$ 7.5). Elution was performed with a gradient of 0 $0.85 \mathrm{M} \mathrm{NaCl}$. The OPPs-containing fractions were identified by chromatography of recombinant OPPs under the same condition, as well as the enzyme ac- tivity assay. The fractions with OPPs activity were pooled and concentrated using YM10 membrane. The concentrated sample was applied to a Superdex G-200 column $(1.6 \times 60 \mathrm{~cm})$ equilibrated with $25 \mathrm{mM}$ Tris (pH 7.5) and $150 \mathrm{mM} \mathrm{NaCl}$. The HMF eluted earlier from the column were collected and examined for their effect in stimulating OPPs activity by carrying out an enzyme assay containing approx. 0.1-0.5 $\mathrm{mg} / \mathrm{ml}$ protein from each fraction.

\subsection{Rapid chemical quench experiments}

The rapid-quench experiments were performed using a Kintek RFQ-3 Rapid Chemical Quench apparatus (Kintek Instruments, TX, USA). For a singleturnover experiment, the reaction was initiated by mixing $15 \mu \mathrm{l}$ of the enzyme preincubated with FPP with an equal volume of $\left[{ }^{14} \mathrm{C}\right] \mathrm{IPP}$ and the final concentrations of UPPs, FPP, and IPP were $10 \mu \mathrm{M}$, $2 \mu \mathrm{M}$, and $50 \mu \mathrm{M}$, respectively, in buffer containing $100 \mathrm{mM}$ HEPES (pH 7.5), $0.5 \mathrm{mM} \mathrm{MgCl}_{2}$, and 50 $\mathrm{mM} \mathrm{KCl}$ at $25^{\circ} \mathrm{C}$ and with or without $0.1 \%$ Triton. Hereafter, the concentrations cited in this paper were those after mixing and during the enzyme reaction. The enzyme reaction was terminated by quenching with $67 \mu \mathrm{l}$ of $0.6 \mathrm{~N} \mathrm{NaOH}$ to give a final concentration of $0.46 \mathrm{~N} \mathrm{NaOH}$. A control was included in each experiment to ensure that the base terminated the enzyme catalysis, which involved the addition of substrates to a premixed solution containing both enzyme and base. The reaction mixture quenched with $0.46 \mathrm{~N} \mathrm{NaOH}$ in a specified time period was extracted with an equal volume of butanol and the radioactivity in the butanol phase was counted using a scintillation counter. The single-turnover time course was calculated from the radiolabeled IPP consumption (the sum of the IPP incorporated into intermediates $\mathrm{C}_{20}-\mathrm{C}_{35}$ and product $\mathrm{C}_{40}$ ) at each specified reaction time. For the identification of the amount of IPP incorporated into intermediates and product at each time point, the formed radiolabeled polyprenyl pyrophosphates were extracted with 1-butanol. Butanol in the solution was dried under $\mathrm{N}_{2}$, and then $20 \%$ propanol, $4.4 \mathrm{U} / \mathrm{ml}$ acidic phosphatase, $0.1 \%$ Triton, and $50 \mathrm{mM}$ sodium acetate $(\mathrm{pH}$ 4.7) were added to convert polyprenyl pyrophosphates to the corresponding polyprenols [19]. Upon completion of the hydrolysis, the polyprenols were 
extracted with $n$-hexane. The volume of hexane was reduced by evaporation and the residual solution was spotted to a reverse phase TLC and developed using acetone/water $(19: 1)$ as the mobile phase [3]. The product distribution was analyzed using a bioimaging analyzer BAS-1500 (Fuji film). The time course of each intermediate during the OPPs single-turnover reaction was generated by combining the data of total $\left[{ }^{14} \mathrm{C}\right] \mathrm{IPP}$ incorporated into intermediates and its distribution among intermediates determined by imagining at every time point of the rapid-quench experiment. The KINSIM computer program was used to simulate the time course data as described below (see Section 2.7) to obtain the rate constant for the IPP condensation reaction.

A multiple-turnover experiment using $1 \mu \mathrm{M}$ enzyme, $50 \mu \mathrm{M}\left[{ }^{14} \mathrm{C}\right] \mathrm{IPP}$ and $6 \mu \mathrm{M}$ FPP was also performed. The enzyme preincubated with FPP was mixed with $\left[{ }^{14} \mathrm{C}\right] \mathrm{IPP}$ at $25^{\circ} \mathrm{C}$ in buffer containing $100 \mathrm{mM}$ HEPES (pH 7.5), $0.5 \mathrm{mM} \mathrm{MgCl}_{2}$ and 50 $\mathrm{mM} \mathrm{KCl}$ in the presence or absence of $0.1 \%$ Triton using the rapid-quench apparatus. The reaction was terminated with $0.46 \mathrm{~N} \mathrm{NaOH}$ and the products were extracted with 1-butanol. The product formation was quantitated from the radioactivity level in the butanol phase relative to that in the aqueous solution. Products were analyzed using the same procedure as described above. The time course data were fit using a burst equation (Eq. 2)

$Y=A \exp \left(-k_{1} t\right)+k_{2} t$

where $Y$ is the concentration of IPP incorporated into intermediates and products, $A$ the observed burst amplitude, $k_{1}$ the rate constant for the exponential phase, and $k_{2}$ the rate constant for the linear component of the reaction.

\subsection{Data simulation}

The KINSIM kinetic program [20] was used to simulate the kinetic data presented in this paper leading to the reaction pathway shown in Scheme 2. The program allows the input of data as $x, y$ pairs from rapid-quench experiments. The single-turnover and multiple-turnover data were fit by a trial and error process to minimize the sum square errors. The $K_{\mathrm{m}}$ and $k_{\text {cat }}$ values were used to constrain the fitting. Since the IPP condensation reaction is irreversible, the simulation process has been simplified, as only one rate constant was needed for each IPP condensation step. In this kinetic pathway as shown in Scheme 2, OPPs binds substrates FPP and IPP and catalyzes five sequential IPP condensation steps resulting in the $\mathrm{C}_{40}$-OPP formation with five rate constants deduced from the time courses of intermediates in the single-turnover reaction.

\subsection{Product distribution}

The reaction mixture containing different concentrations of OPPs, $\left[{ }^{14} \mathrm{C}\right] \mathrm{IPP}$, and FPP as specified in the text was incubated at $25^{\circ} \mathrm{C}$ for $10 \mathrm{~h}$ in a buffer of $100 \mathrm{mM}$ HEPES buffer (pH 7.5), $0.5 \mathrm{mM} \mathrm{MgCl}_{2}$, and $50 \mathrm{mM} \mathrm{KCl}$ with or without $0.1 \%$ Triton $\mathrm{X}$ 100. The reaction was terminated with $10 \mathrm{mM}$ EDTA. We then extracted the products with 1-butanol, evaporated the solvent under $\mathrm{N}_{2}$, prepared the $20 \%$ propanol solution containing acidic pyrophosphatase to convert products, and finally analyzed the polyprenols using TLC as described above.

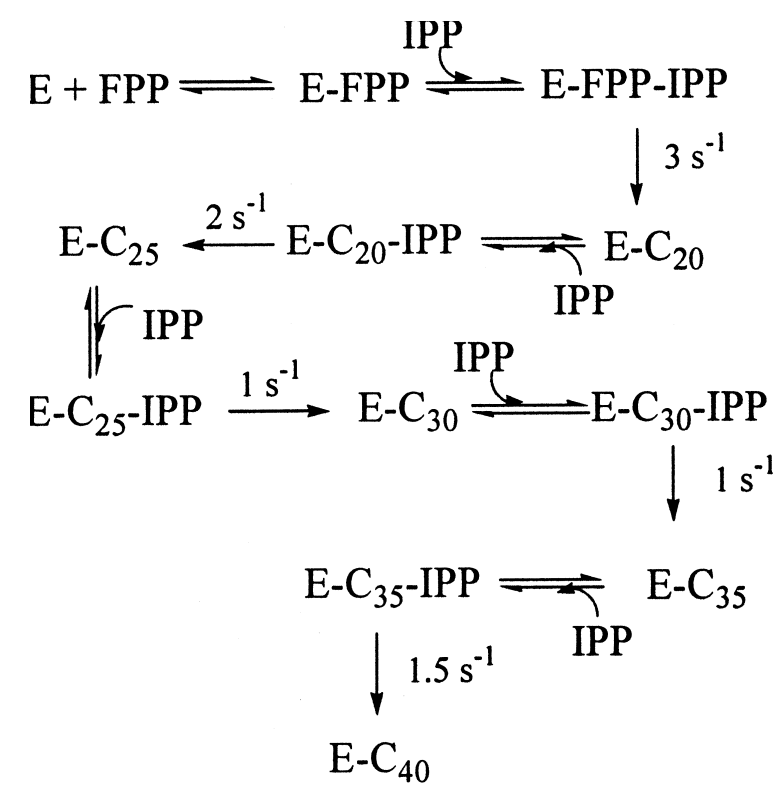

Scheme 2. The proposed kinetic pathway for OPPs catalyzed reaction. 


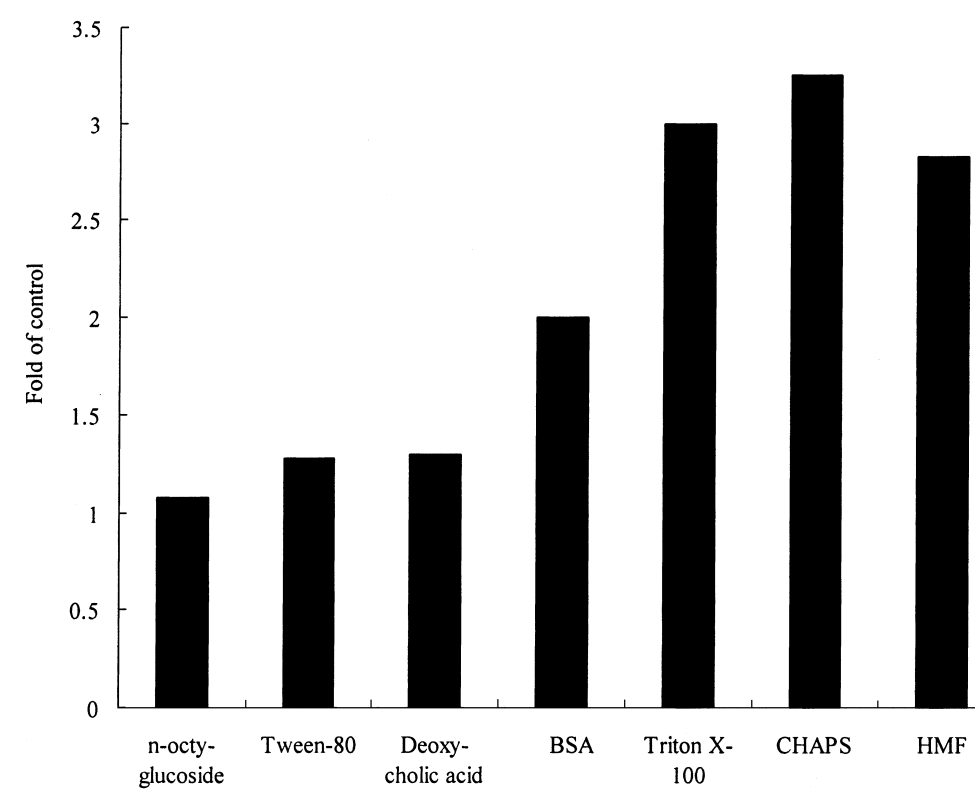

Fig. 1. Rate enhancements of the OPPs reaction using different reagents including $n$-octyl glucoside, Tween 80 , deoxycholic acid, CHAPS and Triton X-100 at $0.1 \%$ final concentration and BSA $(1 \mathrm{mg} / \mathrm{ml})$ and HMF $(0.1-0.5 \mathrm{mg} / \mathrm{ml})$. The reaction rate measured without these reagents was used as a control.

\section{Results}

\subsection{OPPs activities in the absence and presence of activator}

The $k_{\text {cat }}$ value of the OPPs reaction was $0.02 \pm 0.01$ $\mathrm{s}^{-1}\left(k_{\mathrm{cat}}\right.$ was calculated from IPP consumption but not for a complete cycle of OPP formation), and the $K_{\mathrm{m}}$ values for FPP and IPP were determined to be $1.5 \pm 0.4 \mu \mathrm{M}$ and $4 \pm 0.3 \mu \mathrm{M}$, respectively. Since BSA was shown to activate SPPs in M. luteus, as well as Tween 80, a detergent which also demonstrated its stimulating effect on SPPs [13], we have determined the OPPs activity in the presence of BSA and several detergents. The results are summarized in Fig. 1. Among those reagents used, Triton was slightly better in stimulating OPPs activity. In the presence of $0.1 \%$ Triton, the $k_{\text {cat }}$ of the OPPs reaction was $0.06 \pm 0.01 \mathrm{~s}^{-1}$, which was 3 times larger than the $k_{\text {cat }}$ value $\left(0.02 \mathrm{~s}^{-1}\right)$ without Triton. Also shown in Fig. 1, the HMF isolated from $E$. coli cell lysate also increased the OPPs activity by 3 -fold. This result is consistent with the previous observation that HMF causes a 3 times higher SPPs activity in M. luteus [13]. In order to understand whether this activation effect is due to the switch of the rate-determining step, we performed the enzyme single-turnover reaction where OPPs was in excess of FPP. Under such a condition, the enzyme reaction rate is not limited by slow product release, and the IPP condensation rate can be measured.

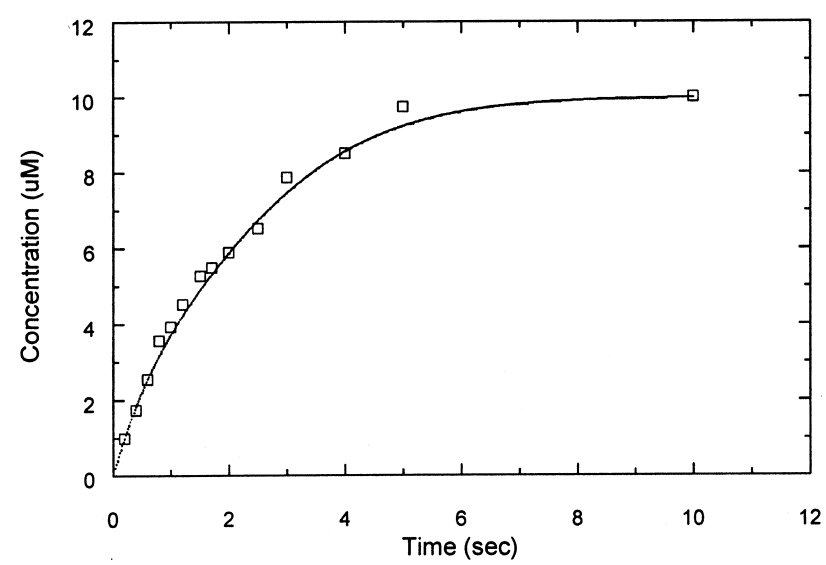

Fig. 2. The single-turnover reaction of OPPs with enzyme in excess of FPP at $\mathrm{pH} 7.5$ and $25^{\circ} \mathrm{C}$. The final concentrations of enzyme, FPP, and $\left[{ }^{14} \mathrm{C}\right] \mathrm{IPP}$ in the reaction mixture were 10 $\mu \mathrm{M}, 2 \mu \mathrm{M}$ and $50 \mu \mathrm{M}$, respectively. The concentration (y-axis) refers to the total concentration of $\left[{ }^{14} \mathrm{C}\right] \mathrm{IPP}$ incorporated into intermediates $\left(\mathrm{C}_{20}-\mathrm{C}_{35}\right)$ and product $\left(\mathrm{C}_{40}\right)$. The solid line represents the fit using KINSIM simulation along with the kinetic pathway and rate constants shown in Scheme 2. 


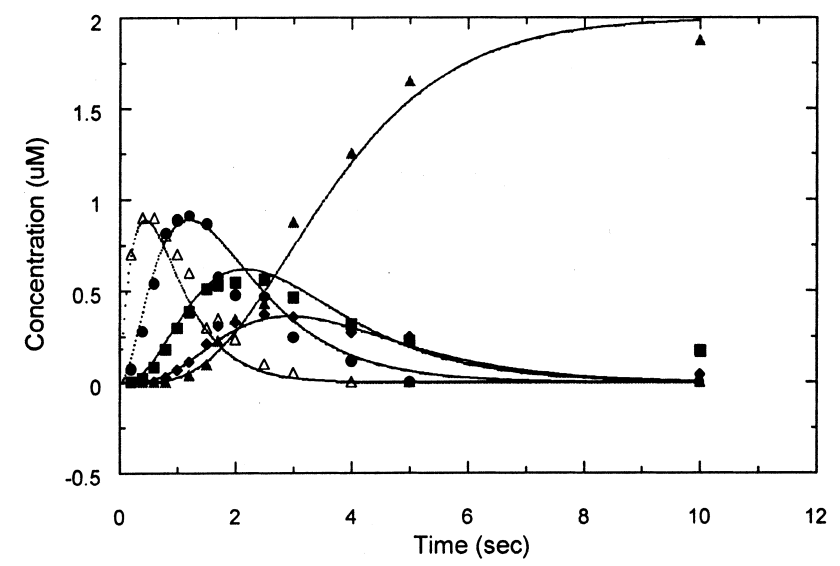

Fig. 3. Single-turnover time courses of intermediates $\left(\mathrm{C}_{20}-\mathrm{C}_{35}\right)$ and product $\left(\mathrm{C}_{40}\right)$ for the OPPs reaction at $\mathrm{pH} 7.5$ and $25^{\circ} \mathrm{C}$. The final concentrations of enzyme, FPP, and $\left[{ }^{14} \mathrm{C}\right]$ IPP in the reaction mixture were $10 \mu \mathrm{M}, 2 \mu \mathrm{M}$ and $50 \mu \mathrm{M}$, respectively. The data represent the time courses of $\mathrm{C}_{20}(\Delta), \mathrm{C}_{25}(\bullet), \mathrm{C}_{30}$ $(\boldsymbol{\square}), \mathrm{C}_{35}(\diamond)$ and $\mathrm{C}_{40}(\boldsymbol{\Delta})$. The fitting curves were obtained from KINSIM simulation using the kinetic pathway of Scheme 2.

\subsection{Enzyme single-turnover experiments}

The formation of intermediates and product was examined under the single-turnover condition with $10 \mu \mathrm{M}$ enzyme, $2 \mu \mathrm{M}$ FPP and $50 \mu \mathrm{M}\left[{ }^{14} \mathrm{C}\right] \mathrm{IPP}$. The time course for the total formation of radiolabeled polyprenyl pyrophosphates during the singleturnover reaction is shown in Fig. 2. Percentages of intermediates $\left(\mathrm{C}_{20}-\mathrm{C}_{35}\right)$ and product $\left(\mathrm{C}_{40}\right)$ at each time point of the single-turnover reaction in the absence of Triton were analyzed using TLC (Fig. 1 of the Supporting Information). By combining the data of the above two figures, the time courses related to intermediates and product yields were determined as shown in Fig. 3. The rate constant of individual IPP condensation obtained by simulation of the time courses (Fig. 3) using the KINSIM program is summarized in the kinetic pathway (Scheme 2). The details of KIMSIM simulation of OPPs single turnover are summarized in Chart 1 of the Supporting Information. The solid curve of Fig. 2 represents the calculated fit using Chart 1 . The rate constant of each of the five IPP condensation steps leading to $\mathrm{C}_{40}$ product formation was similar $\left(2 \pm 1 \mathrm{~s}^{-1}\right)$. In the presence of Triton, similar time courses for intermediates and product (figure not shown) were obtained, suggesting that Triton could not alter the chemical step rate, although its presence could increase the OPPs steady-state rate by 3 times. In order to confirm this observation, a multiple-turnover reaction was performed.

\subsection{Pre-steady-state burst of product formation}

We examined six enzyme turnovers by mixing 1 $\mu \mathrm{M}$ enzyme preincubated with $6 \mu \mathrm{M}$ FPP and 50 $\mu \mathrm{M}\left[{ }^{14} \mathrm{C}\right] \mathrm{IPP}$ using a rapid-quench apparatus. Burst product formation was clearly observed as shown in Fig. 4. The fast initial phase followed by a slow linear phase indicated that the IPP condensation was faster and the rate was then limited by a slower product release. The multiple-turnover OPPs reaction in the presence of $0.1 \%$ Triton was also performed (Fig. 4). Under this condition, the first phase was not altered compared to that in the absence of Triton. However, the second phase exhibited a rate $\left(0.06 \mathrm{~s}^{-1}\right)$ that was 3 times faster, indicating a larger steady-state $k_{\text {cat }}$ value $\left(0.02 \mathrm{~s}^{-1}\right)$ in the presence of $0.1 \%$ Triton. In the absence of Triton, $\mathrm{C}_{45}, \mathrm{C}_{50}, \mathrm{C}_{55}$ and a small amount of $\mathrm{C}_{60}$ polymers were found as the products along with $\mathrm{C}_{40}$-OPP (Fig. 2 of the Supporting Information) but they appeared much later in the time course. The rate of formation of $\mathrm{C}_{45}$ was 100 -fold slower than $2 \mathrm{~s}^{-1}$.

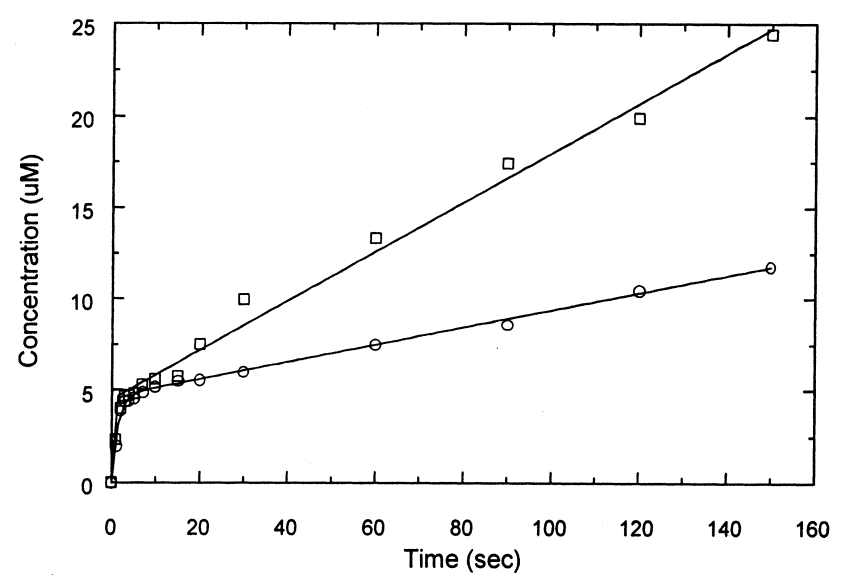

Fig. 4. A pre-steady-state product burst for the OPPs reaction in the absence and presence of $0.1 \%$ Triton at $\mathrm{pH} 7.5$ and $25^{\circ} \mathrm{C}$. The final concentrations of enzyme, FPP, and $\left[{ }^{14} \mathrm{C}\right] \mathrm{IPP}$ in the reaction mixture were $1 \mu \mathrm{M}, 6 \mu \mathrm{M}$ and $50 \mu \mathrm{M}$, respectively. The $y$-axis indicates the total concentration of $\left[{ }^{14} \mathrm{C}\right] \mathrm{IPP}$ incorporated into intermediates $\left(\mathrm{C}_{20}-\mathrm{C}_{35}\right)$ and products $\left(\mathrm{C}_{40}-\mathrm{C}_{60}\right)$. The data represent the time courses of products obtained in the absence $(\bigcirc)$ and presence of $0.1 \%$ Triton $(\square)$. The data were fit using a burst equation (see Section 2). 
Table 1

Product distribution of OPPs catalyzed condensation reactions of IPP with FPP under various conditions

\begin{tabular}{|c|c|c|c|c|c|c|c|c|c|}
\hline \multirow[t]{2}{*}{ Conditions } & \multicolumn{9}{|c|}{ Product $(\%)$} \\
\hline & $\mathrm{C}_{20}$ & $\mathrm{C}_{25}$ & $\mathrm{C}_{30}$ & $\mathrm{C}_{35}$ & $\mathrm{C}_{40}$ & $\mathrm{C}_{45}$ & $\mathrm{C}_{50}$ & $\mathrm{C}_{55}$ & $\mathrm{C}_{60}$ \\
\hline $0.2 \mu \mathrm{M}$ E, $50 \mu \mathrm{M}$ FPP, $50 \mu \mathrm{M}$ IPP & - & - & - & - & 63.57 & 31.69 & 4.75 & - & - \\
\hline $0.2 \mu \mathrm{M}$ E, $5 \mu \mathrm{M}$ FPP, $50 \mu \mathrm{M}$ IPP & - & - & - & - & 51.63 & 34.47 & 10.30 & 2.35 & 1.24 \\
\hline $10 \mu \mathrm{M} \mathrm{E}, 50 \mu \mathrm{M}$ FPP, $1 \mu \mathrm{M}$ IPP & 41.81 & 20.7 & 9.94 & 9.95 & 17.6 & - & - & - & - \\
\hline $10 \mu \mathrm{M}$ E, $0.1 \mu \mathrm{M}$ FPP, $1 \mu \mathrm{M}$ IPP & - & - & - & - & 80.13 & 19.87 & - & - & - \\
\hline $0.2 \mu \mathrm{M}$ E, $50 \mu \mathrm{M}$ FPP, $50 \mu \mathrm{M}$ IPP, $0.1 \%$ Triton & - & - & - & - & 75.98 & 22.52 & 1.5 & - & - \\
\hline $0.2 \mu \mathrm{M}$ E, $5 \mu \mathrm{M}$ FPP, $50 \mu \mathrm{M}$ IPP, $0.1 \%$ Triton & - & - & - & - & 45.35 & 46.12 & 8.5 & 0.35 & - \\
\hline $10 \mu \mathrm{M}$ E, $50 \mu \mathrm{M}$ FPP, $1 \mu \mathrm{M}$ IPP, $0.1 \%$ Triton & 65.76 & 19.6 & 7.48 & 4.98 & 2.18 & - & - & - & - \\
\hline $10 \mu \mathrm{M}$ E, $0.1 \mu \mathrm{M}$ FPP, $1 \mu \mathrm{M}$ IPP, $0.1 \%$ Triton & - & - & - & 3.62 & 92.26 & 4.12 & - & - & - \\
\hline
\end{tabular}

\subsection{Product distribution of OPPs reaction under various conditions}

We have further examined the final products of OPPs under a variety of conditions. The results are shown in Fig. 3 of the Supporting Information and the quantitative data are summarized in Table 1. As shown in lane 1 of the figure, under multiple turnovers with $0.2 \mu \mathrm{M}$ enzyme, $50 \mu \mathrm{M}\left[{ }^{14} \mathrm{C}\right] \mathrm{IPP}$ and 50 $\mu \mathrm{M}$ FPP, $\mathrm{C}_{40}-\mathrm{C}_{50}$ products were formed. With an increased ratio of IPP to FPP (FPP concentration was reduced to $5 \mu \mathrm{M}$ ) as shown in lane 2 , in addition to $\mathrm{C}_{40}-\mathrm{C}_{50}$ products, small amounts of $\mathrm{C}_{55}$ and $\mathrm{C}_{60}$ were also generated. The data of lanes 1 and 2 indicated that FPP could not displace intermediates even at a high concentration $(50 \mu \mathrm{M})$, otherwise the $\mathrm{C}_{20}-\mathrm{C}_{35}$ will be formed as products. Under the same experimental conditions as for lanes 1 and 2, with the only exception that $0.1 \%$ Triton was added, none of the intermediate products was formed with $50 \mu \mathrm{M}$ FPP and $50 \mu \mathrm{M}$ IPP as demonstrated in lanes 5 and 6 . It is apparent that OPPs binds intermediates tightly relative to FPP and Triton did not significantly increase the release rate of the intermediate. Furthermore, an OPPs reaction with $[\mathrm{E} \cdot \mathrm{FPP}]>[\mathrm{IPP}]$ was performed. The reaction shown in lane 3 contained $10 \mu \mathrm{M}$ UPPs, excess of FPP $(50 \mu \mathrm{M})$ and only $1 \mu \mathrm{M}\left[{ }^{14} \mathrm{C}\right] \mathrm{IPP}$. Under such a condition, the E.FPP complex was 10 -fold higher in concentration than IPP and we expected that only $\mathrm{C}_{20}$-geranylgeranyl pyrophosphate could form. Instead, $\mathrm{C}_{20}-\mathrm{C}_{40}$ polymers were generated. As a control reaction shown in lane $4,10 \mu \mathrm{M}$ enzyme catalyzed $\mathrm{C}_{40}$ and a small quantity of $\mathrm{C}_{45}$ formation when the FPP concentration was reduced to $0.1 \mu \mathrm{M}$ and the $\left[{ }^{14} \mathrm{C}\right] \mathrm{IPP}$ con- centration remained $1 \mu \mathrm{M}$. The same reaction carried out in the presence of $0.1 \%$ Triton also resulted in the formation of $\mathrm{C}_{20}-\mathrm{C}_{40}$ (lane 7). The $\mathrm{C}_{40}$ was the product formed in a control experiment as shown in lane 8 .

\section{Discussion}

It is interesting that the Z-type UPPs is significantly activated by the detergent Triton while $E$ type OPPs is not. The $k_{\text {cat }}$ value of the $E$. coli OPPs reaction is $0.02 \mathrm{~s}^{-1}$ and is 3 times larger $\left(0.06 \mathrm{~s}^{-1}\right)$ in the presence of Triton. The rate constant of each IPP condensation measured under single-turnover reaction is approx. $2 \mathrm{~s}^{-1}$ which is 100 times larger than the steady-state $k_{\text {cat }}$ values $(0.02$ $\mathrm{s}^{-1}$ ), suggesting that product release is rate limiting. Triton does not alter the rate of IPP condensation. Rather, Triton accelerates the rate of product release by 3-fold. The pre-steady-state burst of product formation further supports that a step after product formation is rate limiting in the presence and absence of Triton under OPPs multiple turnovers. The fully activated enzyme could display a reaction rate of $2 \mathrm{~s}^{-1}$ (the chemical step rate), which was 100 times larger than the steady-state rate measured in the absence of activator. The high molecular weight fraction of the E. coli cell lysate activates OPPs but with a limited effect of 3-fold, consistent with the observation in M. luteus SPPs. However, there might be an unidentified protein in the lysate or membrane which could cause 100-fold enhancement of OPPs activity.

The OPPs and UPPs enzymes apparently have dif- 
ferent behaviors in product release. However, they show similar chemical step rate constants $\left(2 \mathrm{~s}^{-1}\right.$ vs. $2.5 \mathrm{~s}^{-1}$ ) measured under single-turnover conditions. This indicates that both $E$. coli prenyltransferases require similar activation energies for reactions despite the different stereochemistry of catalysis. The $K_{\mathrm{m}}$ values of FPP and IPP for both enzymes are also similar, suggesting similar substrate affinity. However, from the product distribution pattern of the two enzymes, OPPs might have higher affinities for intermediates compared to UPPs. This is demonstrated by the finding that significant amounts of intermediates were yielded as products under the condition of $50 \mu \mathrm{M}$ FPP and $50 \mu \mathrm{M}$ IPP owing to the displacement of intermediates by FPP in the UPPs reaction, while OPPs produced no intermediate products under the same conditions. This result is also consistent with previously reported SPPs product distribution in which no intermediate product was formed at high concentrations of FPP [21].

Based on crystallographic structural studies, UPPs and OPPs utilize different mechanisms for the IPP condensation they catalyze. The aspartates of DDXXD motifs identified in OPPs and other $E$ type prenyltransferases [22-24] are involved in binding with the pyrophosphate moiety of FPP via $\mathrm{Mg}^{2+}$ [25] and are essential for enzyme catalysis [26-31]. On the other hand, Z-type UPPs lacks the DDXXD motif and the protein-substrate interaction to activate FPP for a nucleophilic attack by IPP remains to be elucidated. For accommodating the product undecaprenyl pyrophosphate (UPP), a tunnel with the surface covered by hydrophobic amino acid residues was found in the structure. This could explain that the detergent Triton is able to facilitate the product release by interfering with the hydrophobic interactions between UPPs and the product. It is unclear yet with regard to the molecular interaction of $E$-type OPPs with its long-chain product.

Several steps, including $\mathrm{PP}_{\mathrm{i}}$ dissociation, relocation of the newly formed allylic pyrophosphate, IPP binding, bond cleavage and formation for 1-4 condensation, are all involved in the process of IPP condensation. As shown in the single-turnover OPPs reaction, the $\mathrm{C}_{15} \rightarrow \mathrm{C}_{20}$ reaction has a similar observed rate compared to the subsequent IPP condensation steps. In the initial step, the enzyme was preincubated with FPP so that $\mathrm{PP}_{\mathrm{i}}$ and allylic pyrophosphate relocations were not included in the reaction kinetics. It appeared that either bond forming or breaking might be rate limiting for IPP condensation in the OPPs reaction. Our results are consistent with the finding that $\mathrm{C}-\mathrm{O}$ bond cleavage of FPP substrate accounts for the rate-limiting step of IPP condensation catalyzed by a geranylgeranyl pyrophosphate synthase [32].

Similar to the UPPs reaction [12], under the condition where E.FPP complex was in 10-fold excess of IPP, polymers larger than $\mathrm{C}_{20}$-polyprenyl pyrophosphates could be generated in the presence and absence of Triton. Previously, we proposed that the UPPs-intermediate complexes have enhanced affinities relative to UPPs.FPP for binding with scarce IPP resulting in the formation of product with the correct chain length [12]. Both $Z$ - and $E$-type prenyltransferases synthesizing long-chain products might utilize this common strategy for making the desired chain lengths.

In summary, a set of rate constants in the OPPs reaction pathway were obtained based on our kinetic data from steady-state and pre-steady-state experiments. Several aspects of the OPPs reaction mechanism are provided by the analysis of this kinetic pathway and product distribution presented here.

\section{Acknowledgements}

This work was supported by a grant (NSC89-2113M-001-061) from the National Science Council of Taiwan to P.-H.L.

\section{References}

[1] K. Ogura, T. Koyama, H. Sagami, Polyprenyl diphosphate synthases, Subcell. Biochem. 28 (1997) 57-87.

[2] K. Ogura, T. Koyama, Enzymatic aspects of isoprenoid chain elongation, Chem. Rev. 98 (1998) 1263-1276.

[3] N. Shimizu, T. Koyama, K. Ogura, Molecular cloning, expression, and purification of undecaprenyl diphosphate synthase. No sequence similarity between E- and Z-prenyl diphosphate synthases, J. Biol. Chem. 273 (1998) 19476-19481.

[4] C.M. Apfel, B. Takacs, M. Fountoulakis, M. Stieger, W. Keck, Use of genomics to identify bacterial undecaprenyl pyrophosphate synthetase: cloning, expression, and characterization of the essential upps gene, J. Bacteriol. 181 (1999) 483-492. 
[5] M. Fujihashi, Y.-W. Zhang, Y. Higuchi, X.-Y. Li, T. Koyama, K. Miki, Crystal structure of cis-prenyl chain elongating enzyme, undecaprenyl diphosphate synthase, Proc. Natl. Acad. Sci. USA 98 (2001) 4337-4342.

[6] T. Baba, C.M. Allen, Prenyl transferase from Micrococcus luteus: characterization of undecaprenyl pyrophosphate synthase, Arch. Biochem. Biophys. 200 (1980) 474- 484.

[7] C.M. Allen, M.V. Keenan, J. Sack, Lactobacillus plantarum undecaprenyl pyrophosphate synthase purification and reaction requirement, Arch. Biochem. Biophys. 175 (1976) 236248.

[8] M.V. Keenan, C.M. Allen, Characterization of undecaprenyl pyrophosphate synthase from Lactobacillus plantarum, Arch. Biochem. Biophys. 161 (1974) 375-383.

[9] C.M. Allen, J.D. Muth, Lipid activation of undecaprenyl pyrophosphate synthase from Lactobacillus plantarum, Biochemistry 16 (1977) 2908-2915.

[10] M.V. Keenan, C.M. Allen, Phospholipid activation of Lactobacillus plantarum undecaprenyl pyrophosphate synthetase, Biochem. Biophys. Res. Commun. 61 (1974) 338-342.

[11] C.M. Allen, Purification and characterization of undecaprenyl pyrophosphate synthase, Methods Enzymol. 110 (1985) 281-299.

[12] J.J. Pan, S.T. Chiu, P.H. Liang, Product distribution and pre-steady-state kinetic analysis of E. coli undecaprenyl pyrophosphate synthase, Biochemistry 39 (2000) 1093610942.

[13] S.-I. Ohnuma, T. Koyama, K. Ogura, Purification of solanesyl-diphosphate synthase from Micrococcus luteus. A new class of prenyltransferase, J. Biol. Chem. 266 (1991) 23706 23713.

[14] S. Fujisaki, T. Nishino, H. Katsuki, Isoprenoid synthesis in Escherichia coli. Separation and partial purification of four enzymes involved in the synthesis, J. Biochem. 99 (1986) $1327-1337$.

[15] K.-I. Asai, S. Fujisaki, Y. Nishimura, T. Nishino, K. Okada, T. Nakagawa, M. Kawamukai, H. Matsuda, The identification of Escherichia coli ispB (cel) gene encoding the octaprenyl diphosphate synthase, Biochem. Biophys. Res. Commun. 202 (1994) 340-345.

[16] K. Okada, K. Suzuki, Y. Kamiya, X. Zhu, S. Fujisaki, Y. Nishimura, T. Nishino, T. Nakagawa, M. Kawamukai, H. Matsuda, Polyprenyl diphosphate synthase essentially defines the length of the side chain of ubiquinone, Biochim. Biophys. Acta 1302 (1996) 217-223.

[17] K. Okada, M. Minehira, X. Zhu, K. Suzuki, T. Nakagawa, H. Matsuda, M. Kawamukai, The ispB gene encoding octaprenyl diphosphate synthase is essential for growth of Escherichia coli, J. Bacteriol. 179 (1997) 3058-3060.

[18] T. Kainou, K. Okada, K. Suzuki, T. Nakagawa, H. Matsuda, M. Kawamukai, Dimer formation of octaprenyl-diphosphate synthase (IspB) is essential for chain length determination of ubiquinone, J. Biol. Chem. 276 (2001) 7876-7883.
[19] H. Fujii, T. Koyama, K. Ogura, Efficient enzymatic hydrolysis of polyprenyl pyrophosphate, Biochim. Biophys. Acta 712 (1982) 716-718.

[20] B.A. Barshop, R.F. Wrenn, C. Frieden, Analysis of numerical methods for computer simulation of kinetic processes: development of KINSIM - a flexible, portable system, Anal. Biochem. 130 (1983) 134-145.

[21] S.-I. Ohnuma, T. Koyama, K. Ogura, Chain length distribution of the products formed in solanesyl diphosphate synthase reaction, J. Biochem. 112 (1992) 743-749.

[22] M.N. Ashby, P.A. Edwards, Elucidation of the deficiency in two yeast coenzyme $Q$ mutants. Characterization of the structural gene encoding hexaprenyl pyrophosphate synthetase, J. Biol. Chem. 265 (1990) 13157-13164.

[23] T. Koyama, S. Obata, M. Osabe, A. Takeshita, K. Yokoyama, M. Uchita, T. Nishino, K. Ogura, Thermostable farnesyl diphosphate synthase of Bacillus stearothermophilus: molecular cloning, sequence determination, overproduction, and purification, J. Biochem. 113 (1993) 355-363.

[24] A. Chen, P.A. Kroon, C.D. Poulter, Isoprenyl diphosphate synthases: protein sequence comparisons, a phylogenetic tree, and predictions of secondary structure, Protein Sci. 3 (1994) 600-607.

[25] L.C. Tarshis, M. Yan, C.D. Poulter, J.C. Sacchettini, Crystal structure of recombinant farnesyl diphosphate synthase at $2.6 \AA$ A resolution, Biochemistry 33 (1994) 10871-10877.

[26] P.F. Marrero, C.D. Poulter, P.A. Edwards, Effects of sitedirected mutagenesis of the highly conserved aspartate residues in domain II of the farnesyl diphosphate synthase activity, J. Biol. Chem. 267 (1992) 21873-21878.

[27] A. Joly, P.A. Edwards, Effect of site-directed mutagenesis of conserved aspartate and arginine residues upon farnesyl diphosphate synthase activity, J. Biol. Chem. 268 (1993) 26983-26989.

[28] L. Song, C.D. Poulter, Yeast farnesyl-diphosphate synthase: site-directed mutagenesis of residues in highly conserved prenyltransferase domains I and II, Proc. Natl. Acad. Sci. USA 91 (1994) 3044-3048.

[29] T. Koyama, M. Tajima, H. Sano, T. Doi, A. Koike-Takeshita, S. Obata, T. Nishino, K. Ogura, Identification of significant residues in the substrate binding site of Bacillus stearothermophilus farnesyl diphosphate synthase, Biochemistry 35 (1996) 9533-9538.

[30] T. Koyama, K. Saito, K. Ogura, S. Obata, A. Takeshita, Thermostable farnesyl diphosphate synthase of Bacillus stearothermophilus: crystallization and site-directed mutagenesis, Can. J. Chem. 72 (1994) 75-79.

[31] L.C. Tarshis, P.J. Proteau, B.A. Kellogg, J.C. Sacchettini, C.D. Poulter, Regulation of product chain length by isoprenyl diphosphate synthases, Proc. Natl. Acad. Sci. USA 93 (1996) 15018-15023.

[32] C.D. Poulter, H.C. Rilling, Prenyltransferase: the mechanism of the reaction, Biochemistry 9 (1976) 1079-1083. 